www.jmscr.igmpublication.org Impact Factor 5.244

Index Copernicus Value: 5.88 ISSN (e)-2347-176x ISSN (p) 2455-0450 crossref DOI:_http://dx.doi.org/10.18535/jmscr/v4i5.13

\author{
Journal Of Medical Science And Clinical Research \\ IGM Publication \\ An Official Publication of IGM Publication
}

\title{
Interphase Fluorescence in Situ Hybridization Analysis of Cytogenetic Abnormalities in Egyptian Patients with Plasma Cell Myeloma
}

\author{
Authors \\ Azza E Hashem ${ }^{1}$, Noha H Boshnak ${ }^{2}$ \\ ${ }^{1} \mathrm{MD}$, Professor of Clinical Pathology, Faculty of Medicine, Ain Shams University, Cairo, Egypt, \\ ${ }^{2} \mathrm{MD}$, Lecturer of Clinical Pathology, Faculty of Medicine, Ain Shams University, Cairo, Egypt, \\ Corresponding Author \\ Noha H Boshnak \\ MD, Lecturer of Clinical Pathology, Faculty of Medicine, Ain Shams University, Cairo, Egypt, \\ Email: nhboshnak@hotmail.com
}

\begin{abstract}
Background: Cytogenetic abnormalities are ubiquitous in plasma cell myeloma representing the hallmark of the disease. These abnormalities have been used as the foundation to establish prognostic factors for accurate risk stratification in plasma cell myeloma. The present study aimed to detect the incidence $14 q 32$ IgH rearrangements, $t(11 ; 14), t(4 ; 14), 13 q$ del and $17 p$ del by Interphase Fluorescence in Situ Hybridization (iFISH) and their relation to the standard prognostic factors and patients' outcome .

Method: Thirty one newly diagnosed Egyptian myeloma patients were tested for the expression of $14 q 32$ IgH rearrangements by using the locus specific identifier (LSI) IGH Dual Color FISH break apart rearrangement probe, we also used the LSI IGH/CCND1 Dual Color Dual Fusion Probe for detection of t(11;14)(q13;q32), LSI IGH/FGFR3 Dual Fusion Probe for detection of t(4;14)(p16;q32), LSI D13S319 (13q14.3) probe for detection of $13 q$ del and LSI TP53 Probe for detection of $17 p$ del on bone marrow samples collected from the patients at diagnosis.

Results: Abnormal iFISH results were found in 21 patients $(67.7 \%)$ of the 31 examined patients. Ten patients $(32.3 \%)$ exhibited $14 q$ IgH rearrangement. Both $t(11 ; 14)$ and $t(4 ; 14)$ were found in 4 patients (12.9\%). 17 pl3 del was detected in 3 patients (9.7\%) while 8 patients (25.8\%) showed positive results for $13 q$ del. There were statistical significant decrease in mean total leucocytic count $(P=0.030)$ and mean serum albumin level $(P=0.008)$ in patients showing positive genetic abnormalities detected by iFISH whereas a significant increase in $\beta 2$-microglobulin level $(>5.5 \mathrm{mg} / \mathrm{dL})(P=0.052)$ and kappa light chain $(P=$ $0.015)$ were found in those patients. A statistically significant lower serum calcium $(<10 \mathrm{mg} / \mathrm{dL})(P=0.050)$ and better outcome $(P=0.012)$ were detected in patients with positive $t(11 ; 14)$ while patients who didn't exhibit t(11:14) had higher serum lactate dehydrogenase (LDH) levels (>300 IU/L) $(P=0.003)$. Patients with positive $t(4 ; 14)$ had significantly older age (over 60 years $)(P=0.018)$ and lower platelet counts $\left(<150 \times 10^{9} / L\right)(P=0.030)$. There was statistical significant decrease found in patients with positive $t(4 ; 14)$ as regards to mean of each of calcium $(P=0.020), L D H(P=0.007)$ and blood urea nitrogen $(B U N)$ serum levels $(P=0.047)$. A strong association has been detected between positive $17 p 13$ del and high mean value of $\beta 2$-microglobulin serum level $(P=0.000)$. Patients who lacked $17 p 13$ del had significantly higher total leucocytic count $\left(>4 \times 10^{9} / L\right)(P=0.002)$. Patients with positive $13 q$ del had significantly lower mean albumin level $(P=0.022)$ and poor outcome $(P=0.005)$.
\end{abstract}


Conclusion: Genetic abnormalities in patients with plasma cell myeloma are important risk factors in terms of outcome. Patients with positive $1(11 ; 14)$ exhibit a better outcome while patients with positive $13 q$ del had poor outcome. $14 q \mathrm{IgH}$ rearrangements was the most common genetic abnormality detected however it wasn't associated with any of the standard prognostic factors.

Keywords: Plasma Cell Myeloma, Fluorescence in Situ Hybridization, Cytogenetic Abnormalities.

\section{INTRODUCTION}

Plasma cell myeloma is a malignant B-cell neoplasm characterized by clonal plasma cell infiltration of the bone marrow ${ }^{[1]}$. It is associated with great heterogeneity at all levels regarding the biological parameters, the clinical manifestations and the prognosis. This heterogeneity is attributed to wide variability of chromosomal aberrations involving many chromosomes that are altered both numerically and structurally ${ }^{[2]}$. Therefore, it appears essential at diagnosis to detect these cytogenetic abnormalities not only because of their prognostic impact, but also because they can be used for measuring response to therapy ${ }^{[3]}$. Because of relatively low rate of proliferation of plasma cells in plasma cell myeloma, many genetic abnormalities couldn't be detected by conventional cytogenetics. Also some of the most important abnormalities may be cryptic even among patients harboring abnormal karyotypes, however interphase fluorescence in situ hybridization (iFISH) is independent of plasma cell division overcoming the limitations of conventional cytogenetics and thus has higher detection rate of these genetic abnormalities ${ }^{[4]}$.

Many primary cytogenetic subtypes have been detected in plasma cell myeloma that can be categorized into two groups: translocations involving the immunoglobulin heavy chain ( $\operatorname{IgH})$ locus on 14q32, (the most common genetic lesion in plasma cell myeloma) and trisomic or hyperdiploid plasma cell myeloma that have trisomies of oddnumbered chromosomes ${ }^{[5],[6]}$. The most common IgH translocations include $\mathrm{t}(11 ; 14), \mathrm{t}(6 ; 14), \mathrm{t}(4 ; 14)$, $\mathrm{t}(14 ; 16)$ and $\mathrm{t}(14 ; 20)$. Additional cytogenetic abnormalities have been detected in plasma cell myeloma either from the onset of the disease such as monosomy $13 / 13 q$ del or mainly with disease progression such as $17 \mathrm{p} \mathrm{del}{ }^{[7]}$.
This study aimed to detect $14 \mathrm{q} 32 \quad \mathrm{IgH}$ rearrangements, $\{\mathrm{t}(4 ; 11, \mathrm{t}(4 ; 14)\}, 13 \mathrm{q}$ del and $17 \mathrm{p}$ del by interphase FISH in Egyptian patients with plasma cell myeloma and to determine the relationships of these chromosomal abnormalities with standard prognostic parameters and patients' outcome .

\section{PATIENTS AND METHOD}

\subsection{Patients}

The study was approved by the committee of Medical Research Ethics, Medical School, Ain Shams University; an informed written consent was obtained from all studied patients. A total of 31 newly diagnosed Egyptian patients with plasma cell myeloma referred to Ain Shams University Hospitals were enrolled in this study. The diagnosis of plasma cell myeloma was established according to the criteria of the WHO outlined in $2008^{[8]}$. The patients were classified into stage I, II and III according to the International Staging System for multiple myeloma ${ }^{[9]}$. All the patients underwent full history taking, thorough clinical examination and laboratory investigations including complete blood count (CBC) using Coulter LH750 cell counter (Coulter, Electronics, Hialeah, FL, USA), with examination of Leishman stained peripheral blood (PB) smears for differential leucocytic count, erythrocyte sedimentation rate (ESR), albumin, total protein, calcium, creatinine, blood urea nitrogen (BUN), lactate dehydrogenase (LDH) and $\beta 2$ microglobulin level $(\beta 2-\mathrm{M})$ together with serum protein electrophoresis and immunofixation studies of serum and/or urine to confirm the presence of Mband and detect the type of the immunoglobulin (Ig) heavy chain and its light chain type, also 24-hour urine collection for light chain (Bence-Jones protein) excretion. Bone marrow aspiration was done for all the patients for morphological 
examination of Leishman-stained smears and for interphase FISH analysis.

\subsection{Method}

\section{Interphase FISH analysis}

Bone marrow samples $(2 \mathrm{~mL})$ were obtained from each patient under complete aseptic conditions. Samples were collected in a sterile preservative free heparin coated vacutainer. Interphase FISH technique was only done at the time of diagnosis using the Vysis

Patients' samples were assessed using the following probes:

- Locus specific identifier (LSI) IGH dual color, break apart rearrangement probe for $14 q 32$ gene rearrangements, normal cells show two yellow fusion signals (juxtaposed red and green signals) denoting normal IgH $14 q 32$ gene rearrangement. In positive cells for $\mathrm{IgH} 14 \mathrm{q} 32$ gene rearrangement, one red and one green signal corresponding to $\operatorname{IgH}$ $14 q 32$ gene rearrangement and one yellow fusion signal corresponding to normal $\operatorname{IgH}$ $14 \mathrm{q} 32$ gene rearrangement are seen in $>6 \%$ of examined cells (Figure 1).

- LSI IGH/CCND1 Dual Color Dual Fusion Probes for detection of $\mathrm{t}(11 ; 14)(\mathrm{q} 13 ; \mathrm{q} 32)$, normal cells show two red and two green signals. In positive cells for $\mathrm{t}(11 ; 14)$ (q13;q32), two yellow fusion signals in addition to one red and one green signals were detected in $>1.3 \%$ of examined cells (Figure 2).

- By using the LSI IGH/FGFR3 Dual Fusion Probe for detection of $\mathrm{t}(4 ; 14)(\mathrm{p} 16 ; \mathrm{q} 32)$, normal cells show two red and two green signals. In positive cells for $\mathrm{t}(4 ; 14)$ (p16;q32), two yellow fusion signals in addition to one red and one green signals were detected in $>1.3 \%$ of examined cells (Figure 3).

- LSI D13S319 (13q14.3) probe for 13q14 deletion, normal cells show 2 red signals corresponding to the normal $13 \mathrm{q} 14$ gene and

2 green signals corresponding to the two centromeres (used as control). In positive cells with 13q14 deletion gene, two green signals and only one red signal corresponding to the deletion in the long arm of chromosome 13, region 1 band 4 are seen in $>6 \%$ of examined cells (Figure 4 ).

- LSI TP53 Probe maps to the $17 \mathrm{p} 13.1$ region on chromosome 17 containing the p53 gene for detection of P53 gene deletion, normal cells show two red signals. In positive cells for deletion p53 gene, one red signal only was detected in $>6 \%$ of examined cells.

\subsection{Statistical analysis}

Statistical analyses were done using the SPSS statistical software (SPSS 15.O.1 for windows; SPSS Inc, Chicago, IL,2001). Descriptive quantitative data were shown as mean or median, range values, \pm standard deviation $(\mathrm{SD})$ while descriptive qualitative data was presented as number and percentage. Independent-Samples $\mathrm{T}$ test was used to evaluate the statistical significance of the difference between two study group means. ChiSquare test and Fisher exact test used to examine the relationship between two qualitative variables. Statistical difference was considered significant if $P$-value was $<0.05 \&$ highly significant if $P$-value was $<0.001$.

\section{RESULTS}

\subsection{Descriptive analysis for demographic and laboratory parameters of the studied patients}

This study was carried out on 31 newly diagnosed multiple myeloma patients. Seventeen $(54.8 \%)$ of them were males and 14 (45.2\%) were females with male to female ratio of $1.2: 1$. Their ages ranged from 21 to 76 years with mean of $56.23 \pm 11.90$ and median age was 59 years. The basic demograghic and laboratory parameters of the studied patients were summarized in Table 1.

\subsection{Genetic abnormalities detected by iFISH}

A total of 21 patients (67.7\%) exhibited abnormal iFISH results, $14 \mathrm{q}$ IGH rearrangement was the most common genetic abnormality being detected in 10 
patients $(32.3 \%)$, both $\mathrm{t}(11 ; 14)$ and $\mathrm{t}(4 ; 14)$ were detected in 4 patients $(12.9 \%)$. Three patients $(9.7 \%)$ showed positive results for $17 \mathrm{p} 13$ del while 8 patients $(25.8 \%)$ showed positive results for $13 q$ del. Ten patients $(32.3 \%)$ did not exhibit any of the studied abnormalities.

\subsection{Comparison between iFISH abnormalities and the standard prognostic factors}

No significant differences in gender and age $(<60$ years versus $\geq 60$ years) were identified between patients with positive iFISH results and those without an abnormality. However, in comparison to patients with normal iFISH results, patients with abnormal iFISH results exhibited higher $\beta 2-\mathrm{M}$ serum level $(P=0.052)$, advanced ISS $(P=0.030)$ and poor outcome $(P=0.029)$. Also, There were statistical significant decrease found in patients with positive iFISH abnormalities as regards to their mean total leucocytic count $(P=0.030)$ and mean serum albumin level $(P=0.008)$. Light chain kappa was exhibited in 17 patients $(81 \%)$ with positive iFISH abnormalitites versus 4 patients (19\%) who had Lambda light chain type $(P=0.015)$ (Table 2$)$.

There were no statistical significant differences found in the patients with positive $14 \mathrm{q} 32 \mathrm{IgH}$ rearrangements as regards to their demographic and laboratory findings.

A significant differences in age $(P=0.040)$ were identified between patients with positive $\mathrm{t}(11 ; 14)$ results and those without an abnormality. Patients with positive $\mathrm{t}(11 ; 14)$ exhibited lower calcium serum levels $(<10 \mathrm{mg} / \mathrm{dL})(P=0.050)$ and favorable outcome $(P=0.012)$, while patients who lacked $\mathrm{t}(11 ; 14)$ had statistically significant higher level of LDH serum levels $(>300 \mathrm{IU} / \mathrm{L})(P=0.003)$ (Table 3).

A significant increase in age $(\geq 60$ years: $P=0.018)$ and a significant decrease in platelets count $\left(<150 \times 10^{9} / \mathrm{L}: P=0.030\right)$ were identified in patients with positive $\mathrm{t}(4 ; 14)$ results, where 4 patients $(100 \%)$ were $\geq 60$ years while no one with this abnormality was $<60$ years, also 3 patients $(75 \%)$ had platelets count $<150 \times 10^{9} / \mathrm{L}$ while only one patient $(25 \%)$ had platelets count $\geq 150 \times 10^{9} / \mathrm{L}$.
Patients with positive $\mathrm{t}(4 ; 14)$ exhibited significant decrease as regards to mean of each of calcium, LDH and BUN serum levels $(P=0.020,0.007$ and 0.047 respectively). Patients with positive $17 \mathrm{p} 13$ del exhibited significantly higher $\beta 2 \mathrm{M}$ serum levels $(P=0.000)$. Patients who lacked $17 \mathrm{p} 13$ del had significantly higher total leucocytic count $\left(>4 \times 10^{9} / \mathrm{L}\right)(P=0.002)$ (Table 3$)$.

There was a statistical significant decrease found in patients with positive $13 \mathrm{q}$ del as regards to their mean albumin level $(P=0.022) .8$ patients $(100 \%)$ with positive $13 \mathrm{q}$ del exhibited a poor outcome $(P=$ 0.005) (Table 3).

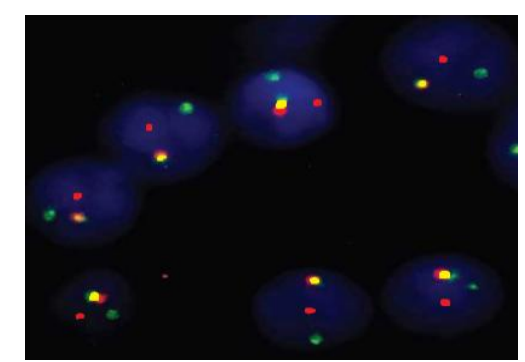

Figure (1): iFISH analysis positive for $14 \mathrm{q} 32$ rearrangements identified by the presence of one yellow signal representing region 3 band 2 of normal copy of chromosome 14,1 red signal and 1 green signal (break apart signal) of rearranged chromosome 14.

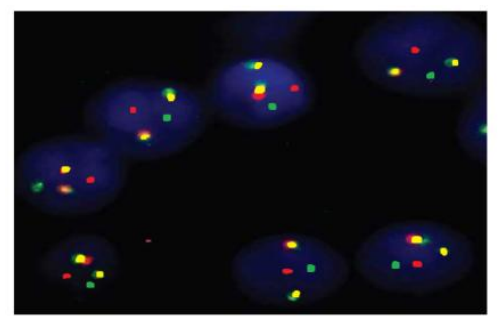

Figure (2): iFISH analysis positive for $\mathrm{t}(11 ; 14)(\mathrm{q} 13 ; \mathrm{q} 32) \quad \mathrm{IGH} / \mathrm{CCND} 1$, showing two yellow fusion signals (double fusion) in addition to one red and one green signals.

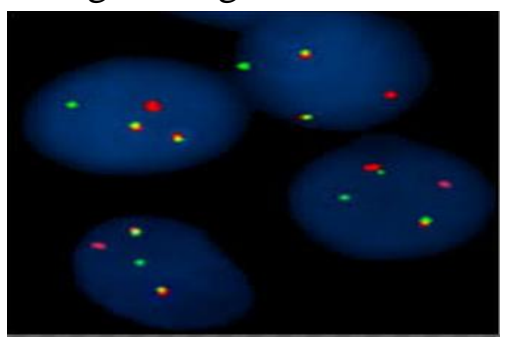

Figure (3): iFISH positive for $t(4 ; 14)(p 16 ; q 32)$ IGH/FGFR3, identified by the presence of two yellow fusion signals, one red and one green. 


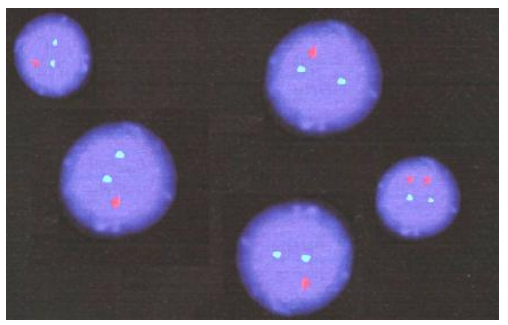

only representing region 1 band 4 of one copy of chromosome 13, while the other is deleted. The 2 green signals represent the 2 centromeres of both copies of chromosome 13 .

Figure (4): iFISH analysis positive for $13 q 14$ deletion identified by the presence of one red signal

Table (1): Descriptive analysis for demographic and laboratory parameters of the studied patients $(\mathrm{n}=31)$

\begin{tabular}{|l|c|c|}
\hline Parameters & Range & Mean \pm SD \\
\hline Age $(\mathrm{yrs})$ & $21-76$ & $56.23 \pm 11.90$ \\
\hline Total leucocytic count $\left(\mathrm{x} 10^{9} / \mathrm{L}\right)$ & $3.6-20.2$ & $7.36 \pm 3.21$ \\
\hline Hemoglobin $(\mathrm{g} / \mathrm{dL})$ & $4.1-13.5$ & $8.06 \pm 1.76$ \\
\hline Platelets $\left(\mathrm{x} 10^{9} / \mathrm{L}\right)$ & $40-360$ & $206.45 \pm 85.55$ \\
\hline$\beta 2-$-microglobulin $(\mathrm{mg} / \mathrm{dL})$ & $2.1-26.6$ & $6.57 \pm 4.95$ \\
\hline Albumin $(\mathrm{g} / \mathrm{dL})$ & $1.3-4.1$ & $2.87 \pm 0.78$ \\
\hline Total protein $(\mathrm{g} / \mathrm{dL})$ & $5.4-10.8$ & $8.19 \pm 1.27$ \\
\hline Calcium $(\mathrm{mg} / \mathrm{dL})$ & $8.2-14.7$ & $11.12 \pm 1.92$ \\
\hline LDH $(\mathrm{IU} / \mathrm{L})$ & $172-622$ & $465.97 \pm 124.77$ \\
\hline Creatinine $(\mathrm{mg} / \mathrm{dL})$ & $0.6-14.3$ & $3.84 \pm 3.23$ \\
\hline BUN $(\mathrm{mg} / \mathrm{dL})$ & $6-97$ & $49.06 \pm 25.36$ \\
\hline ESR $(\mathrm{mm} / \mathrm{hr})$ & $102-198$ & $139.42 \pm 21.97$ \\
\hline Parameters & Value & $\mathrm{n}(\%)$ \\
\hline \multirow{2}{*}{ Bence-Jones protein } & Negative & $26(83.9 \%)$ \\
\hline \multirow{2}{*}{ Light chain type } & Positive & $5(16.1 \%)$ \\
\hline \multirow{3}{*}{ Stage } & Kappa & $21(67.7 \%)$ \\
\cline { 2 - 3 } & Lambda & $10(32.3 \%)$ \\
\cline { 2 - 3 } & I & $7(22.6 \%)$ \\
\cline { 2 - 3 } & II & $10(32.3 \%)$ \\
\cline { 2 - 3 } & III & $14(45.2 \%)$ \\
\hline
\end{tabular}

Abbreviations: LDH, lactate dehydrogenase; BUN, blood urea nitrogen;

ESR, erythrocyte sedimentation rate.

Table (2): Comparison between iFISH abnormalities and the standard prognostic factors

\begin{tabular}{|c|c|c|c|c|}
\hline \multicolumn{2}{|l|}{ Parameter } & $\begin{array}{l}\text { Negative } \\
\text { genetic abnormalities }(n=10)\end{array}$ & $\begin{array}{l}\text { Positive } \\
\text { genetic abnormalities }(n=21)\end{array}$ & $P$-value \\
\hline Total leucocytic count $\left(\mathrm{x} 10^{9} / \mathrm{L}\right)$ & Mean \pm SD & $9.14 \pm 4.61$ & $6.51 \pm 1.88$ & $0.030 * *$ \\
\hline $\beta 2$-microglobulin (mg/dL) & $\begin{array}{c}<3.5 \mathrm{n}(\%) \\
3.5-5.5 \mathrm{n}(\%) \\
>5.5 \mathrm{n}(\%)\end{array}$ & $\begin{array}{l}5(50.0 \%) \\
3(30.0 \%) \\
2(20.0 \%)\end{array}$ & $\begin{array}{c}3(14.3 \%) \\
5(23.8 \%) \\
13(61.9 \%)\end{array}$ & $0.052 *$ \\
\hline Albumin (g/dL) & Mean \pm SD & $3.39 \pm 0.47$ & $2.62 \pm 0.78$ & $0.008 * *$ \\
\hline Light chain type & $\begin{array}{l}\text { Kappa } \mathrm{n}(\%) \\
\text { Lambda } \mathrm{n}(\%)\end{array}$ & $\begin{array}{l}4(40.00 \%) \\
6(60.00 \%)\end{array}$ & $\begin{array}{c}17(81.00 \%) \\
4(19.00 \%)\end{array}$ & $0.015^{*}$ \\
\hline Stage & $\begin{array}{c}\text { I } \mathrm{n}(\%) \\
\text { II } \mathrm{n}(\%) \\
\text { III } \mathrm{n}(\%)\end{array}$ & $\begin{array}{l}5(50.00 \%) \\
3(30.00 \%) \\
2(20.00 \%)\end{array}$ & $\begin{array}{c}2(9.50 \%) \\
7(33.30 \%) \\
12(57.10 \%)\end{array}$ & $0.030 *$ \\
\hline Outcome & $\begin{array}{c}\text { Poor } \mathrm{n}(\%) \\
\text { Favorable } \mathrm{n}(\%)\end{array}$ & $\begin{array}{l}3(30.00 \%) \\
7(70.00 \%)\end{array}$ & $\begin{array}{c}15(71.40 \%) \\
6(28.60 \%)\end{array}$ & $0.029 *$ \\
\hline
\end{tabular}

*Chi square test

**T-test 
Table (3): Comparison between each of the studied iFISH abnormalities and the standard prognostic factors

\begin{tabular}{|c|c|c|c|c|}
\hline \multicolumn{2}{|l|}{ Parameters } & \multirow{2}{*}{$\begin{array}{c}\mathrm{t}(11 ; 14) \\
\text { Negative }(\mathrm{n}=27) \\
54.56 \pm 11.80\end{array}$} & \multirow{2}{*}{$\begin{array}{c}\mathrm{t}(11 ; 14) \\
\text { Positive }(\mathrm{n}=4) \\
67.50 \pm 3.87\end{array}$} & \multirow{2}{*}{$\begin{array}{l}P \text {-value } \\
0.040 * *\end{array}$} \\
\hline Age (yrs) & Mean \pm SD & & & \\
\hline Calcium (mg/dL) & $\begin{array}{l}<10 \mathrm{n}(\%) \\
\geq 10 \mathrm{n}(\%) \\
\end{array}$ & $\begin{array}{c}7(25.9 \%) \\
20(74.1 \%) \\
\end{array}$ & $\begin{array}{l}3(75.0 \%) \\
1(25.0 \%) \\
\end{array}$ & $0.050 *$ \\
\hline LDH (IU/L) & $\begin{array}{l}<300 \mathrm{n}(\%) \\
\geq 300 \mathrm{n}(\%) \\
\end{array}$ & $\begin{array}{c}1(3.7 \%) \\
26(96.3 \%) \\
\end{array}$ & $\begin{array}{l}2(50.0 \%) \\
2(50.0 \%) \\
\end{array}$ & $0.003 *$ \\
\hline Outcome & $\begin{array}{c}\text { Poor } \mathrm{n}(\%) \\
\text { Favorable } \mathrm{n}(\%)\end{array}$ & $\begin{array}{c}18(66.7 \%) \\
9(33.3 \%)\end{array}$ & $\begin{array}{c}0(0.0 \%) \\
4(100.0 \%)\end{array}$ & $0.012 *$ \\
\hline & & $\begin{array}{c}\mathrm{t}(4 ; 14) \\
\text { Negative }(\mathrm{n}=27)\end{array}$ & $\begin{array}{c}\mathrm{t}(4 ; 14) \\
\text { Positive }(\mathrm{n}=4) \\
\end{array}$ & \\
\hline Age(yrs) & $\begin{array}{l}<60 \mathrm{n}(\%) \\
\geq 60 \mathrm{n}(\%) \\
\end{array}$ & $\begin{array}{l}17(63.0 \%) \\
10(37.0 \%) \\
\end{array}$ & $\begin{array}{c}0(0.0 \%) \\
4(100.0 \%) \\
\end{array}$ & $0.018 *$ \\
\hline Platelets (x10/L) & $\begin{array}{l}<150 \mathrm{n}(\%) \\
\geq 150 \mathrm{n}(\%) \\
\end{array}$ & $\begin{array}{c}6(22.2 \%) \\
21(77.8 \%) \\
\end{array}$ & $\begin{array}{l}3(75.0 \%) \\
1(25.0 \%) \\
\end{array}$ & $0.030 *$ \\
\hline Calcium (mg/dL) & Mean \pm SD & $11.43 \pm 1.86$ & $9.08 \pm 0.84$ & $0.020 * *$ \\
\hline LDH (IU/L) & Mean \pm SD & $488.33 \pm 109.11$ & $315.00 \pm 132.67$ & $0.007 * *$ \\
\hline BUN (mg/dL) & Mean \pm SD & $52.52 \pm 23.20$ & $25.75 \pm 30.52$ & $0.047 * *$ \\
\hline & & $\begin{array}{c}17 \mathrm{p} 13 \text { del } \\
\text { Negative }(\mathrm{n}=28)\end{array}$ & $\begin{array}{c}17 \mathrm{p} 13 \text { del } \\
\text { Positive }(\mathrm{n}=3)\end{array}$ & \\
\hline Total leucocytic count $\left(\times 10^{9} / \mathrm{L}\right)$ & $\begin{array}{l}<4 \mathrm{n}(\%) \\
\geq 4 \mathrm{n}(\%) \\
\end{array}$ & $\begin{array}{c}0(0.0 \%) \\
28(100.0 \%) \\
\end{array}$ & $\begin{array}{l}1(33.3 \%) \\
2(66.7 \%) \\
\end{array}$ & $0.002 *$ \\
\hline 及2-microglobulin (mg/dL) & Mean \pm SD & $5.61 \pm 3.25$ & $15.57 \pm 9.56$ & $0.000 * *$ \\
\hline & & $\begin{array}{c}13 q \text { del } \\
\text { Negative }(n=23)\end{array}$ & $\begin{array}{c}13 q \text { del } \\
\text { Positive }(n=8)\end{array}$ & \\
\hline Albumin (g/dL)) & Mean \pm SD & $3.06 \pm 0.69$ & $2.34 \pm 0.81$ & $0.022 * *$ \\
\hline Outcome & $\begin{array}{c}\text { Poor } \mathrm{n}(\%) \\
\text { Favorable } \mathrm{n}(\%)\end{array}$ & $\begin{array}{l}10(43.5 \%) \\
13(56.5 \%)\end{array}$ & $\begin{array}{c}8(100.0 \%) \\
0(0.0 \%)\end{array}$ & $0.005^{*}$ \\
\hline
\end{tabular}

*Chi square test

**T-test

\section{DISSCUSION}

Plasma cell myeloma is characterized by high genetic instability leading to various numerical and structural chromosomal aberrations ${ }^{[10]}$. Detection of these aberrations provided fundamental insights into the genetic basis of the pathogenesis of the disease and is of crucial importance because of their association with unique biologic, clinical, and prognostic features ${ }^{[11],[12]}$. The present study was planned to determine the incidences of $14 q 32 \operatorname{IgH}$ rearrangements, $\{\mathrm{t}(4 ; 14)$ and $\mathrm{t}(11 ; 14)\}$ as well as $13 \mathrm{q}$ del and $17 \mathrm{p}$ del by iFISH performed in 31 newly diagnosed Egyptian myeloma patients as well as the relationships of these chromosomal abnormalities with the standard prognostic parameters and patients' outcome .

Prognostic factors for plasma cell myeloma have been suggested, and the International Staging System (ISS) is the most widely applied. It stratifies patients by their albumin and $\beta 2$-microglobulin levels ${ }^{[13]}$. Regarding patients' clinical staging in the present study according to the international staging system, 7 patients $(22.6 \%)$ were in stage I, which was nearly similar to Jekarl et al. (2013) $(21.5 \%)^{[4]}$, however it was lower than that reported in the Chinese study by Chen et al. (2007) $(45.8 \%){ }^{[3]}$, and Shin et al. (2015) (32.4\%) ${ }^{[13]}$ in their recent Korean study. On the contrary, it was higher than that detected by Liu et al. (2015) $(10.5 \%)^{[14]}$ whose Chinese study included 107 newly diagnosed patients.

Regarding stage II, 10 patients (32.3\%) were detected in this study which was nearly similar to that reported by Chen et al. (2007) (33.3\%) ${ }^{[3]}$, while it was marginally lower than that observed by Liu et al. (2015) (37.1\%) ${ }^{[14]}$, Shin et al. (2015) (39.7\%) [13], and Jekarl et al. (2013) (43.9\%) ${ }^{[4]}$. In the current study, 14 patients $(45.2 \%)$ were in stage III, which was higher than that reported by Jekarl et al. 
(2013) (34.6\%) [4], Shin et al. (2015) (27.9\%) ${ }^{[13]}$, and Chen et al. (2007) (20.8\%) ${ }^{[3]}$, while it was less than that mentioned by Liu et al. (2015) $(52.4 \%)^{[14]}$. The presence of genetic abnormalities in plasma cells has been considered to be an important prognostic factor, and several genetic abnormalities have been extensively investigated during the past decade ${ }^{[15]}$. In the present study, a total of 21 patients $(67.7 \%)$ exhibited abnormal iFISH results which was consistent with what reported by Jekarl et al. (2013) $(63.1 \%)^{[4]}$. On the contrary, it was higher than that observed by Liu et al. (2015) $(46.6 \%)^{[14]}$.

In the present study, 14q IGH rearrangements was the most common genetic abnormality being detected in $32.3 \%$ of the patients which was near to what reported by Kim et al. (2014) $(32.5 \%)^{[16]}$ and Jekarl et al. (2013) (29.2\%) ${ }^{[4]}$, but it was much lower than that observed by Gao et al. (2012) (70\%) ${ }^{[17]}$, Chen et al. (2007) $(60.4 \%)^{[3]}$ who used enriched CD138 myeloma cells by MACS (magnetic activated cell sorting) to improve the sensitivity of the interphase FISH method and this may explain the higher frequency in their study. Yuregir et al. (2009) [18] who were studying chromosomal aberrations including 13q14 deletion and $14 \mathrm{q} 32 \mathrm{IgH}$ rearrangement by both FISH and conventional cytogenetics found that $58.3 \%$ of the patients had 14q IGH rearrangement. On the other hand, it was much higher than reported by Kassem et al. (2014) (20\%) ${ }^{[19]}$ in their Egyptian study.

In the current study, $\mathrm{t}(11 ; 14)$ was detected in $12.9 \%$ of the patients which was marginally lower than that observed by Fonesca et al. (2003) (15.8\%) ${ }^{[20]}$ who used cytoplasmic Ig enhanced iFISH, Jekarl et al. (2013) $(16.2 \%)^{[4]}$. Also nearly same results were reported by $\mathrm{Kim}$ et al. (2014) (17\%) ${ }^{[16]}$ in their large Asian study where 500 patients from several Asian countries were included, and Liu et al. (2015) $(17.5 \%)^{[14]}$.

As regards to $\mathrm{t}(4 ; 14)$, it was detected in $12.9 \%$ of the patients in our study which was similar to what mentioned by Jekarl et al. (2013) (11.5\%) ${ }^{[4]}$, Fonesca et al. (2003) (12.7\%) ${ }^{[20]}$ and Avet-loiseau et al. (2007) $(14 \%)^{[21]}$, who studied the genetic abnormalities and their prognostic impact in 1064 MM patients enrolled in the IFM 99 trials conducted by the Intergroup Francophone du Myelome. However, it was higher than that observed by Kim et al. (2014) (10.5\%) ${ }^{[16]}$, and Liu et al. (2015) $(6.9 \%)^{[14]}$.

Regarding the analysis of $17 \mathrm{p} 13 \mathrm{del}$, the present study showed that $9.7 \%$ of patients showed positive results for $17 \mathrm{p} 13 \mathrm{del}$. which was near to that observed by Jekarl et al. (2013) $(10.8 \%)^{[4]}$, Liu et al. (2015) $(10.7 \%)^{[14]}$ and Fonesca et al. (2003) $(10.7 \%)^{[20]}$. On the other hand, it was less than reported by Kim et al. (2014) $(13.3 \%)^{[16]}$.

In the present study, $25.8 \%$ of the patients showed positive results for $13 q$ del which was lower than what was reported by the Egyptian study by Kassem et al. (2014) $(30 \%)^{[19]}$. While it was much lower than that observed by Fonesca et al. (2003) (54.2\%) ${ }^{[20]}$, Zhan et al. (2006) $(50 \%){ }^{[22]}$ who were studying the role of cytogenetics by FISH and conventional cytogenetics (Karyotyping) in myeloma patients using a larger scale of patients (794 and 1064), Hu et al. (2011) (47.2\%) ${ }^{[11]}$ and Turkman et al. (2014) $(44 \%)^{[23]}$.

The observed differences in the previous results may be explained by the use of different scales of patients examined in different researches and different techniques adopted by different researchers such as the use of MACs in combination with iFISH to substantially enhance the sensitivity of the cytogenetic analysis ${ }^{[3]}$. Variations in the size of the IgH probe signals can also occur as a result of normally occurring deletions and rearrangements within the $\operatorname{IgH}$ gene leading to problems in the interpretation of both positive and negative results. In addition to various genetic, cultural, environmental, social and racial differences noted among different populations for example, the incidence of multiple myeloma in Asians is relatively lower than Caucasians ${ }^{[16]}$.

Prognostic criteria for MM were applied according to the International Staging System (ISS), which provides two advantages over the traditional DurieSalmon system. The ISS relies on widely available laboratory parameters (albumin and $\beta 2 \mathrm{M}$ ) which 
indicate the tumor bulk, renal function and the patients' general state. Also, it allocates patients to equally sized patients groups with markedly different prognoses. In contrast, the Durie-Salmon system depends on the subjective evaluation of the extent of bone involvement and usually results in an imbalanced distribution of patients (more patients are categorized as stage III than as stage I or II) ${ }^{[9]}$. In the present study, patients with abnormal iFISH results exhibited higher $\beta 2$-microglobulin serum level similar to what reported by Liu et al. (2015) ${ }^{[14]}$. We found an association between advanced ISS and patients with positive iFISH abnormalities. On the other hand, by Liu et al. (2015) ${ }^{[14]}$ found that ISS was not affected by the presence or absence of any known iFISH abnormality. An association between hemoglobin levels and iFISH abnormalities was statistically insignificant in the present study, however Jekarl et al. (2013) ${ }^{[4]}$ and Liu et al. (2015) [14] found an association between low hemoglobin levels $(<10 \mathrm{~g} / \mathrm{dL})$ and positive iFISH abnormalities. In the current study, there were no statistical significant differences found in patients with positive iFISH abnormalities and their serum calcium levels. However, Liu et al. (2015) ${ }^{[14]}$ had found that patients with abnormal iFISH results exhibited significantly higher calcium levels. We didn't found significant difference in gender or age between patients with positive iFISH results and those without an abnormality and this is consistent with what was reported by Liu et al. (2015) ${ }^{[14]}$.

Chromosomal abnormalities of $14 \mathrm{q} 32$ are the most frequent chromosomal abnormalities, which have been observed in about $75 \%$ of patients with plasma cell myeloma and have been associated in the oncogenesis of $\mathrm{MM}^{[24]}$.

In our study, there were no statistical significant differences found in the patients with positive $14 \mathrm{q} 32 \mathrm{IgH}$ rearrangements as regards to their demographic and laboratory findings. On the other hand Avet-loisseau et al. (2002) ${ }^{[25]}$ found strong association between $\beta 2$-microglobulin $>3 \mathrm{mg} / \mathrm{dL}$ and $14 \mathrm{q} 32$ abnormalities $(P<0.001)$. We also found no statistical significant differences as regards to the outcome of $14 \mathrm{q} 32 \mathrm{IgH}$ rearrangements positive patients which was coincided with that obtained by Kassem et al. (2014) ${ }^{[19]}$ in their Egytptian study.

Chromosome translocations involving the $\mathrm{IgH}$ gene locus define distinct entities of multiple myeloma with clinical, morphologic, immunophenotypic, and therapeutic implications. The two most common IgH translocations are $\mathrm{t}(4 ; 14)(\mathrm{p} 16.3 ; \mathrm{q} 32)$ and $\mathrm{t}(11 ; 14)(\mathrm{q} 13 ; \mathrm{q} 32)$. These translocations result from illegitimate IgH rearrangements. The presence of these rearrangements has been correlated with morphology (plasmablastic with $\mathrm{t}(4 ; 14)(\mathrm{p} 16.3 ; \mathrm{q} 32)$ and lymphoplasmacytic or small mature with $\mathrm{t}(11 ; 14)(\mathrm{q} 13 ; \mathrm{q} 32))$ and tumor mass. It has been suggested that patients with $\mathrm{t}(11 ; 14)$ have better survival and response to treatment, particularly high-dose therapy and stem cell support. In contrast, patients with $\mathrm{t}(4 ; 14)(\mathrm{p} 16.3 ; \mathrm{q} 32)$ have an inferior outcome, regardless of the mode of treatment (conventional or high dose) ${ }^{[26]}$.

We identified a significant differences in age between patients with positive $t(11 ; 14)$ results and those without this abnormality. However, Gertz et al. (2005) [26] did not find an association between patients with positive $t(11 ; 14)$ and their ages. In the present study, patients who lack $t(11 ; 14)$ exhibited higher LDH serum levels $(>300 \mathrm{IU} / \mathrm{L})(P=0.003)$. However, Gertz et al. (2005) ${ }^{[26]}$ did not find an association between positive $\mathrm{t}(11 ; 14)$ and $\mathrm{LDH}$ serum levels. We did not find a significant association in patients with positive $t(11 ; 14)$ as regards to their serum creatinine and $\beta 2 \mathrm{M}$, consistent with what mentioned by Gertz et al. $(2005)^{[26]}$. Jekarl et al. (2013) ${ }^{[4]}$ had found that $\mathrm{t}(11 ; 14)$ was associated with higher albumin levels $(P=0.016)$, but correlation between serum albumin and $t(11 ; 14)$ was statistically insignificant in our study. In the current study, $\mathrm{t}(11 ; 14)$ was associated with a favourable outcome which coincided with what was reported in a study by Jekarl et al. (2013) ${ }^{[4]}$ as well as Fonesca et al. (2003) ${ }^{[20]}$.

In the present study, a significant increase in age $(\geq$ 60 years: $P=0.018)$ was identified in patients with positive $t(4 ; 14)$ results consistent with what reported in the studies by Bulter et al. (2012) ${ }^{[27]}$ and Jekarl et al. (2013) ${ }^{[4]}$. While in the study by Gertz and his 
colleagues in $2005^{[26]}$, age was not significantly different between patients who had $t(4 ; 14)$ and those who didn't exhibit that translocation.

In the current study, patients with positive $t(4 ; 14)$ exhibited a statistical significant decrease as regard to their mean LDH serum level. But Gertz et al. (2005) [26] found that LDH had no significant difference among those patients. We did not find an association between patients with positive $t(4 ; 14)$ and their albumin levels and hemoglobin levels. On the other hand Liu et al. (2015) ${ }^{[14]}$ had revealed that in comparison to patients who lacked $t(4 ; 14)$, the patients with $\mathrm{t}(4 ; 14)$ had significantly lower albumin levels $(P=0.008)$ and lower hemoglobin levels $(P<0.001)$. We did not find an association between patients with positive $t(4 ; 14)$ and their $\beta 2 \mathrm{M}$ consistent with what observed by Gertz et al. (2005) [26]. On the contrarily, Gao et al. (2012) ${ }^{[28]}$ and $\mathrm{Hu}$ et al. (2011) ${ }^{[11]}$ found that patients with $\mathrm{t}(4 ; 14)$ had significant higher $\beta 2 \mathrm{M}$ predicting a poor outcome.

Chromosome 17 deletion at 17 p13 with alterations of tumor suppressor gene p53 is seen in about one fifth of the MM patients. It represents the highest risk in all MM genetic categories. These patients have a shorter survival, lower possibility of response and are prone to develop extramedullary diseases, hypercalcemia and plasmacytomas ${ }^{[11]}$.

In our study, patients with positive $17 \mathrm{p} 13$ del exhibited significantly higher $\beta 2 \mathrm{M}$ serum levels as mentioned by Fonesca et al. (2003) ${ }^{[20]}$. On the other hand, Gertz et al. (2005) ${ }^{[26]}$ found no differences between $\beta 2 \mathrm{M}$ and positivity of $17 \mathrm{p} 13 \mathrm{del}$.

We found no significance in patients with positive 17 p13 del as regard to their hemoglobin levels, platelets count and serum creatinine levels. But according to Jekarl et al. (2013) ${ }^{[4]}$ low hemoglobin levels $(<10 \mathrm{~g} / \mathrm{dL}) \quad(\mathrm{P}=0.005)$, low platelet count $\left(<150 \times 10^{9} / \mathrm{L}\right)(\mathrm{P}=0.006)$ and higher creatinine levels $(>1.2 \mathrm{mg} / \mathrm{dL}) \quad(\mathrm{P}=0.02)$ were frequently found in patients with positive $17 \mathrm{p} 13 \mathrm{del}$. In the current study, there were no correlation between the presence of $17 \mathrm{p} 13$ del and age, creatinine and LDH similar to what reported by Gertz et al. (2005) ${ }^{[26]}$. Chromosome 13 abnormalities are highly prevalent in MM and other plasma cell disorders. In most cases, chromosome 13 abnormalities present monosomy of chromosome 13, however available karyotypic data suggest that interstitial deletions, predominately involving band 13q14 are observed. Other detailed FISH studies showed that in most cases (80-90\%), of chromosome 13 abnormalities are representative of chromosome 13 monosomy, whereas the remaining $15 \%$ of cases have interstitial deletions [29], [30], [31]. Most of these studies have not ruled out the possibility that other loci may be involved in deletions in $\mathrm{MM}^{[31]}$.

We did not find an association between hemoglobin levels and 13q14 del. However, Jekarl et al. (2013)

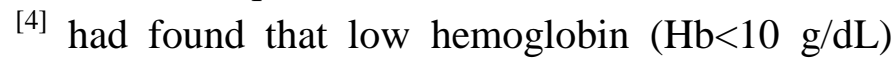
levels were frequently associated with $13 \mathrm{q} 14$ del $(P=0.029)$.

There was a statistical association between 13q14 del and a poor outcome which coincided with what was reported by Harrison et al. (2003) ${ }^{[32]}$, Deng et al. (2007) ${ }^{[33]}$ and Kassem et al. (2014) ${ }^{[19]}$.

In conclusion, our study illustrates that $14 \mathrm{q} \operatorname{IgH}$ rearrangements was the most common genetic abnormality being detected in $32.3 \%$ among the studied Egyptian patients, however it wasn't associated with any of the standard prognostic factors. Genetic abnormalities in patients with plasma cell myeloma are important risk factors in terms of outcome. Patients with positive $t(11 ; 14)$ exhibit a favourable outcome while patients with positive $13 \mathrm{q}$ del had poor outcome. Longer follow up period for at least 2 years is recommended for correlation of genetic abnormalities with clinical prognosis together with application of other FISH probes as $1 \mathrm{q} 21$ and $\mathrm{t}(14 ; 16)(\mathrm{q} 32 ; \mathrm{q} 23)$ for the accurate detection of the exact incidence of chromosomal aberrations among the Egyptian myeloma patients and application of iFISH during the follow up period of patients (after receiving treatment) for the detection of molecular remission.

\section{REFERENCES}

1. Palumbo and K. Anderson, "Multiple myelom," N Engl J Med, vol. 364, pp. 10461060, 2011. 
2. H. Avet-Loiseau, F. Magrangeas, P. Moreau, et al, "Molecular heterogeneity of multiple myeloma: pathogenesis, prognosis, and therapeutic implications," J Clin Oncol, vol. 29, pp. 1893-1887, 2011.

3. L. Chen, J. Li, W. Xu, et al, "Molecular cytogenetic aberrations in patients with multiple myeloma studied by interphase fluorescence in situ hybridization," Exp Oncol, vol. 29, pp. 116-20, 2007.

4. D. Jerkarl, C. Min, A. kwon, et al, "Impact of genetic abnormalities on the prognosis and clinical parameters of patients with multiple myeloma," Ann Lab Med, vol. 33, pp. 248-254, 2013.

5. S. Kumar, R. Fonseca, RP. Ketterling, et al, "Trisomies in multiple myeloma: impact on survival in patients with high-risk cytogenetics," Blood, vol. 119, pp. 2100-2105, 2012.

6. R. Fonseca, PL. Bergsagel, J. Drach, et al, "International Myeloma Working Group molecular classification of multiple myeloma: spotlight review," Leukemia, vol. 23, pp. 2210-2221, 2009.

7. Greenberg, S. Philip, A. Paner et al, "Racial differences in primary cytogenic abnormaliti-es in multiple myeloma: a multicenter study," Blood cancer J, vol. 4, pp. e271, 2015.

8. SH Swerdlow, E Campo, NL Harris, et al, editors. WHO classification of Tumours of haematopoietic and lymphoid tissues, 4th Lyon, France: IARC Press, 2008.

9. P. Greipp, J. San Miguel, B. Durie, et al, "International staging system for multiple myeloma," J Clin Oncol, vol. 23, pp. 34123420, 2005.

10. K. Hanlon, L. Harries, S. Ellard, et al, "Evaluation of 13q14 status in multiple myeloma by digital single nucleotide polymorphism technology," J Mol Diagn, vol. 11, pp. 450-457, 2009.

11. Y. Hu, L. Chen, C. Sun, et al, "Clinical significance of chromosomal abnormalities detected by interphase fluorescence in situ hybridization in newly diagnosed multiple myeloma patients," Chin Med J, vol. 124, pp. 2981-2985, 2011.

12. Streekantaiah C, "FISH panels for hematologic malignancies," Cytogenet Genome Res, vol. 118, pp. 284-296, 2007.

13. S. Shin, S. Lee, H. Kim, et al, "Antigen Expression Patterns of Plasma Cell Myeloma: An Association of Cytogenetic Abnormality and International Staging System (ISS) for Myeloma," J Clin Lab Anal, vol. 6, pp. 505-510, 2015.

14. N. Liu, H. Zhou, G. Yang, et al, "Retrospective analysis of genetic abnormalities and survival in 131 patients with multiple myeloma," Oncol Lett, vol. 9, pp. 930-936, 2015.

15. S. Wuilleme, N. Robillard, L. Lodé, et al, "Ploidy, as detected by fluorescence in situ hybridization, defines different subgroups in multiple myeloma," Leukemia, vol. 19, pp. 275-278, 2005.

16. K. Kim, J. Lee, J. Kim, et al, "Clinical profiles of multiple myeloma in Asia: An Asian Myeloma Network study," Am J Hematol, vol. 89, pp. 751-756, 2014.

17. X. Gao, C. Li, R. Zhang, et al, " Fluorescence in situ hybridization analysis of chromosome aberrations in 60 Chinese patients with multiple myeloma," Med Oncol J, vol. 29, pp. 2200-2206, 2012.

18. O. Yuregir, F. Sahin, Z. Yilmaz, et al, "Fluorescent in situ hybridization studies in multiple myeloma," Hematol J, vol. 14, pp. 90-94, 2009.

19. N Kassem, D. Elswefy, N. Eman, et al, "Prognostic value of $13 \mathrm{q} 14$ deletion and $\operatorname{IgH}$ $14 q 32$ rearrangement by interphase fluorescence in situ hybridization in patients with multiple myeloma," J Appl Hematol, vol. 5, pp. 141-147, 2014.

20. R. Fonesca, E. Blood, M. Rue, et al "Clinical and biologic implications of recurrent genomic aberrations in myeloma," Blood, vol. 101, pp. 4569-4575, 2003. 
21. Avet-loiseau H, Atta M, Moreau P, et al. (2007): Genetic abnormalities and survival in multiple myeloma: the experience of the Intergroupe Francophone du Myelome. Blood; 109(8): 3489-95.

22. F. Zhan, J. Sawyer and G. Tricot, "The role of cytogenetics in myeloma," Leukemia, vol. 20, pp. 1484-1486, 2006.

23. S.Turkmen, A. Binder, A. Gerlach, et al, "High prevalence of immunoglobulin light chain gene aberations as revealed by FISH in multiple myeloma and MGUS," Genes Chromosomes Cancer, vol. 53, pp. 650-656, 2014.

24. Schmidt-Wolf, A. Glasmacher, C. Hahn-Ast, et al, "Chromosomal aberrations in 130 patients with multiple myeloma studied by interphase FISH: diagnostic and prognostic relevance," Cancer Genet Cytogenet, vol. 167, pp. 20-25, 2006.

25. H. Avet-loisseau, T. Facon, B. Grosbois, et $\mathrm{Al}$, "Oncogenesis of multiple myeloma: 14q32 and 13q chromosomal abnormalities are not randomly distributed, but correlate with natural history, immunological features, and clinical presentation," Blood, vol. 99, pp. 2185-2191, 2002.

26. M. Gertz, M. Lacy, A. Dispenzieri, et al, "Clinical implications of $\mathrm{t}(11 ; 14)(\mathrm{q} 13 ; \mathrm{q} 32)$, $\mathrm{t}(4 ; 14)(\mathrm{p} 16.3 ; \mathrm{q} 32)$, and $17 \mathrm{p} 13$ in myeloma patients treated with high-dose therapy," Blood, vol. 106, 2837-2840, 2005.

27. Butler, D. Wolff, Y. Kang, et al, "Association of age with fluorescence in situ hybridization abnormalities in multiple myeloma reveals higher rate of IGH translocations among older patients," Leuk Lymphoma, vol. 53, pp. 2444-2448, 2012.

28. X. Gao, C. Li, R. Zhang, et al, "Fluorescence in situ hybridization analysis of chromosome aberrations in 60 Chinese patients with multiple myeloma," Med Oncol, vol. 29, pp. 2200-2206, 2012.

29. H. Avet-Loiseau, A. Daviet, S. Saunier, et al, "chromosome 13 abnormalities in multiple myeloma are mostly monosmy $13, "$ Br J Haematol, vol. 111, pp. 1116-1117, 2000.

30. R. Fonseca, M. Oken, D. Harrington, et al, "Deletions of chromosome 13 in multiple myeloma identified by iFISH usually denote large deletions of the q-arm or monosomy," Leukemia, vol. 15, pp. 981-986, 2001.

31. R. Fonseca, B. Barlogie, R. Bataille, et al, "Genetics and cytogenetics of multiple myeloma (a workshop report)," Cancer Res, vol. 64, pp. 1546-1558, 2004.

32. Harrison, H. Mazzullo, K. Cheung, et al, "Cytogenetics of multiple myeloma: Interpretation of fluorescence in situ hybridization results," $\mathrm{Br} \mathrm{J}$ Haematol, vol. 120, pp. 944-952, 2003.

33. S. Deng, Y. Xu, Y. Wang, et al, "Cytogenetic characteristics of patients with multiple myeloma in China: Analysis of 100 case," Zhonghua Yi Xue Za Zhi, vol. 87, pp. 1685-1688, 2007. 